\title{
Economic Evaluation of a Soft Ankle Brace Compared to Tape in Acute Lateral Ankle Ligamentous Sprains
}

\author{
Ellen Kemler ${ }^{1 *}$, Mark R Krist ${ }^{1}$, Ingrid GL van de Port ${ }^{1,2}$, Arno W Hoes ${ }^{3}$, G Ardine de Wit ${ }^{3,4}$ and Frank JG Backx ${ }^{1}$ \\ ${ }^{1}$ Rudolf Magnus Institute of Neuroscience, Department of Rehabilitation, Nursing Science and Sports, University Medical Centre Utrecht, The Netherlands \\ ${ }^{2}$ Revant Rehabilitation Centre, Breda, The Netherlands \\ ${ }^{3}$ Julius Center for Health Sciences and Primary Care, University Medical Centre Utrecht, The Netherlands \\ ${ }^{4}$ National Institute of Public Health and the Environment, Bilthoven, The Netherlands
}

"Corresponding author: Ellen Kemler, Rudolf Magnus Institute of Neuroscience, Department of Rehabilitation, Nursing Science and Sports, University Medical Centre Utrecht, W01.121, P.O. Box 85500, 3508 GA Utrecht, The Netherlands, Tel: + 316 16242309; Fax: + 3188 7555450; E-mail: h.j.kemler-2@umcutrecht.nl

Rec date: May 02, 2016; Acc date: Oct 21, 2016; Pub date: Oct 28, 2016

Copyright: (C) 2016 Kemler E, et al. This is an open-access article distributed under the terms of the Creative Commons Attribution License, which permits unrestricted use, distribution, and reproduction in any medium, provided the original author and source are credited.

\begin{abstract}
Background: Ankle sprains are common injuries, associated with high healthcare and societal costs. After sustaining an acute ankle sprain, ankle taping is the standard treatment in the Netherlands. Ankle braces are sometimes used as an alternative. The aim of the present study was to assess the costs-effectiveness of soft ankle bracing compared to ankle tape treatment in patients with an acute lateral ankle ligamentous sprain (ALALS).

Methods: We conducted an economic evaluation from a societal perspective alongside a controlled trial. In order of presentation, patients were alternately allocated to four week treatment with a soft ankle brace or four week treatment with ankle tape. Costs and clinical outcomes with respect to re-injuries were derived from online patient questionnaires at $5,9,13,26,39$, and 52 weeks after inclusion. Univariate and probabilistic sensitivity analyses were performed. Cost-effectiveness was assessed using bootstrapping with 5000 replications.
\end{abstract}

Results: In total 157 patients with an ALALS were included, of which 151 (tape $n=76$, brace $n=75$ ) were analyzed. After one-year of follow-up, no significant clinical differences were found between both treatments groups. Mean total costs were $€ 1,634$ (SD 261) per patient in the brace group and $€ 1,846$ (SD 296) per patient in the tape group; mean difference $-€ 212(95 \% \mathrm{Cl}-854$ to 436$)$. The use of an ankle brace was less expensive in $71 \%$ of the bootstrap replications.

Conclusions: In patients with ALALS, soft ankle bracing compared to ankle taping had similar clinical effect. The costs of soft bracing were lower. However, this difference was not statistically significant.

Keywords Ankle sprain; Soft brace; Ankle tape; Cost-effectiveness; Re-injuries

\section{Introduction}

The lateral ankle sprain is one of the most common injuries. Incidence rates of 1.5-7 per 1000 person-years have been reported in emergency departments in the general European population [1-3]. The total number of ankle injuries (medically and non-medically treated) related to sports activities and other activities of daily living increased from 19.0 to 26.6 per 1000 person-years over the period 2000-2010 [1]. In the Netherlands, the number of sports-related ankle injuries is estimated to be 650.000 each year [4].

The mean total costs of an ankle sprain were estimated at $€ 360.60$ [5], corresponding to a total cost of $€ 234$ million a year. These high direct healthcare costs are the result of medical consumption, (sometimes longstanding) rehabilitation [6,7], persistent residual symptoms [6-8] and high recurrence rates $[6,9,10]$.

Furthermore, ankle sprains may cause sick leave, especially in the first period after the trauma [11]. The mean duration of sick leave of medically treated ankle sprains is 2.5 weeks in the Netherlands, with $90 \%$ having resumed work after 6 weeks [12].

After the acute phase, the current trend in treatment of ALALS is functional treatment $[11,13-15]$, as it is shown to be more effective compared to treatment using immobilization $[11,16,17]$.

Reviews and guidelines therefore recommend functional treatment of ALALS [18,19], although a short-period of immobilization might be desirable in the acute phase of severe ankle sprains to reduce pain and swollen ness $[15,20]$.

Functional treatment consists of early-mobilization and weightbearing with semi-rigid external support, combined with neuromuscular training $[6,21]$.

For external support an ankle brace or tape can be used. A recent review of Lin et al. concluded that the current evidence regarding costs-effectiveness of ankle sprain treatment is limited [22].

The aim of the present study was to compare the costs-effectiveness of soft ankle bracing and ankle tape treatment in patients with an ALALS. 


\section{Methods}

\section{Participants and setting}

This economic evaluation was carried out alongside a pragmatic controlled trial. Details of the study design have been published elsewhere [23]. In summary, patients with an ALALS were eligible for the study. They were recruited from 20 general practitioner practices, 9 physiotherapist practices and 2 emergency departments (EDs). Patients (both athletes and non-athletes) had to be 18 years or older and diagnosed with an ALALS caused by an inversion trauma and were recruited between May 2006 and October 2008. Patients were excluded if they sustained an eversion ankle sprain, multilevel or complex injury, or previously had surgery of the same ankle. Patients diagnosed as having a mental illness or cognitive impairment were also excluded from this study.

\section{Study design and procedure}

All eligible patients were referred to the UMC Utrecht Department of Sports Medicine. The research assistant contacted the patients by phone and conducted the first screening for inclusion and exclusion criteria (age, multiple trauma, complicated trauma, history of surgery) by means of a short standard questionnaire. If patients were eligible for inclusion, the research assistant allocated them to the brace or tape group based on the order of presentation. To check if the patients were indeed eligible for inclusion, a sports physician conducted a baseline assessment. The protocol was approved by the medical ethics committee (Institutional Review Board) of the University Medical Centre Utrecht (UMCU) and was registered in the Dutch trial register (ISRCTN92030205). Written informed consent was provided by all patients.

\section{Treatment}

All patients were treated with Immobilization, Compression, and Elevation (ICE) during the first 2-12 days after the onset of the ALALS. The duration of the ICE treatment depended on the swollenness of the injured ankle. The allocated intervention started as soon as possible, but at least within 14 days after the initial trauma [23].

Patients in the brace group received instructions from the sports physician about using and applying the soft brace. They were instructed to wear the soft ankle brace for four weeks, except at night and when taking a shower. The soft ankle brace (type Push; manufacturer NEA Int) is based on the principle of functional ankle tape bandage. The control group received the usual care in the Netherlands, namely four weeks of ankle taping [24]. According to daily practice, the athletic tape bandage was applied by the general practitioner, primary care assistant, physical therapist, or plaster technician. After 2 weeks the tape was replaced.

\section{Sample size}

The incidences of ALALS recurrences were expected to be similar in both treatment groups. However, a clinically worthwhile difference for interventions, (i.e., the difference or the ratio of the cumulative incidence of re-injury between the two treatments) was not available to use for an a priori sample size calculation. Thus, we aimed to include as many participants as possible in this study within a period of 30 months.

\section{Data collection and outcomes}

After informed consent was obtained, baseline data were obtained by the sports physicians. These data consisted of standardized history taking and a physical examination of the ankles. At fixed times after inclusion $(5,9,13,26,39$ weeks), patients received a (digital) questionnaire. Information was registered about ankle re-sprains, residual symptoms, compliance with the allocated treatment, absenteeism from paid- and unpaid work (hours) and from school, sport resumption, medical consumption (volumes of medical resources used) and costs of treatments (out-of-pocket costs). One year after treatment allocation, all patients were invited for a reassessment by one of the sports physicians.

All the sports physicians received a standardized training on assessing the outcomes. This assessment included the same physical examination as at baseline and completion of a final questionnaire as indicated above.

In this economic evaluation, the primary clinical outcome was the proportion of patients reporting re-sprains within one-year follow-up after the initial ALALS. A re-injury was defined as a new inversion trauma at the same ankle, as reported by the patient.

\section{Economic framework}

Economic analysis was performed from a societal perspective $[25,26]$. The economic evaluation was designed as a cost-effectiveness analysis (CEA) [25]. The difference in mean total costs per patient between both treatment groups and the mean difference in number of recurrent ankle sprains between the groups were calculated. Discounting was not applied as the time horizon of this study did not exceed 1 year.

\section{Costs}

All costs within one-year related to the initial ALALS or a recurrent ankle sprain were registered. Costs were divided in intervention costs, direct healthcare costs (medical costs), direct non-healthcare costs (patient costs, i.e., related to use of complementary medicine and medical devices) and indirect non-healthcare costs.

The first contact moment (after onset of injury) with a general practitioner (GP), physiotherapist or visit to an emergency department (ED) was not reported by all patients. Intervention costs for patients in the brace group were therefore standardized to one ED visit and the costs of the soft ankle brace.

The intervention costs for patients in the tape group were determined as one ED visit, one GP visit (guideline directed refreshment of tape after two weeks) and ankle tape. The total costs were the sum of intervention costs, direct healthcare costs, direct nonhealthcare costs and indirect non-healthcare costs.

The mean costs per patient in both treatment groups were calculated. Cost calculations were performed according to the Dutch guidelines for cost calculations in healthcare [25]. All costs were calculated for the year 2009, the last year of data collection for the clinical study.

\section{Direct healthcare costs}

The direct healthcare costs consisted of costs for visiting the GP, medical specialist, physical therapist, and costs related to diagnostic 
testing (i.e., imaging, including ultrasound), and medication. Medication use was reported by the patient.

Medication costs were estimated on the basis of prices communicated by the Pharmacotherapeutical Compass (2009) as provided by the Dutch Healthcare Insurance Board [27]. Costs were computed by multiplying the volumes of use by standardized costs prices.

\section{Direct non-healthcare costs}

The direct non-healthcare costs consisted of costs for complementary medicine consultation and medical devices. These costs were analysed as reported by the patient.

\section{Indirect non-healthcare costs}

Costs related to absenteeism from (un)paid work and school were incorporated as indirect non-healthcare costs. In this study the maximum reported period of productivity-losses was 13 weeks. The costs per hour for productivity losses related to a paid job was based on age and sex dependent income of the Dutch population (see Appendix A). A shadow price of $€ 12.50$ per hour was applied to productivity loss for household and volunteer work [25]. To calculate the costs for absenteeism from school the costs price for employing someone at the age of 23 (net minimal youth wages) was used (set at $€ 8.07$ per hour) [25].

\section{Statistical analysis}

Differences in costs and effects were analysed according to the intention-to-treat principle. Baseline characteristics between both groups were analysed with Chi-square test or Fisher-exact test for dichotomous outcome and the independent student t-test or MannWhitney for continuous variables. The differences in the proportion of ankle sprains recurrences between the brace and tape two group were analyzed using Chi-square analyses, controlling for differences between the two groups at baseline.

Cost-effectiveness pairs were obtained by bootstrapping with 5000 replications. Cost-effectiveness planes were obtained by plotting the incremental costs (vertical axis) against the incremental effects (horizontal axis) of each single bootstrap [28]. Four sensitivity analyses were performed: 1 ) from a health care perspective, i.e., only including healthcare costs and excluding all costs outside health care; 2) with complete cases only (66 in the brace group and 68 in the tape group), excluding cases with missing data; 3) with exclusion of costs for absenteeism from unpaid work and school, i.e., only including productivity losses associated with paid work; and 4) with exclusion of seven participants who sustained other ankle injuries than an ankle sprain (e.g. ankle fracture or overload injury).

Participants were asked to fill out six questionnaires during one year follow-up. Eleven percent of the cases $(n=17)$ in our study were not fully complete at the end of our clinical trial. Costs relating to missing health care resources use, out of pocket costs, and productivity losses (3.9\% of all our data points) were imputed using the last observation carried forward. Multiple imputation was used to assess missing data $(\mathrm{n}=12)$ for ankle sprain recurrences

The analyses were performed using IBM SPSS 23.0 for Windows and Microsoft Excel. All tests were two-tailed and a $p$ value $<0.05$ was considered statistically significant.

\section{Results}

Of the total 164 patients who were assessed for eligibility in this study, seven patients were excluded for different reasons (Figure 1). After allocation, another 6 participants were excluded because they were unwilling to complete any study questionnaire (brace $=2$, tape $=4$ ).

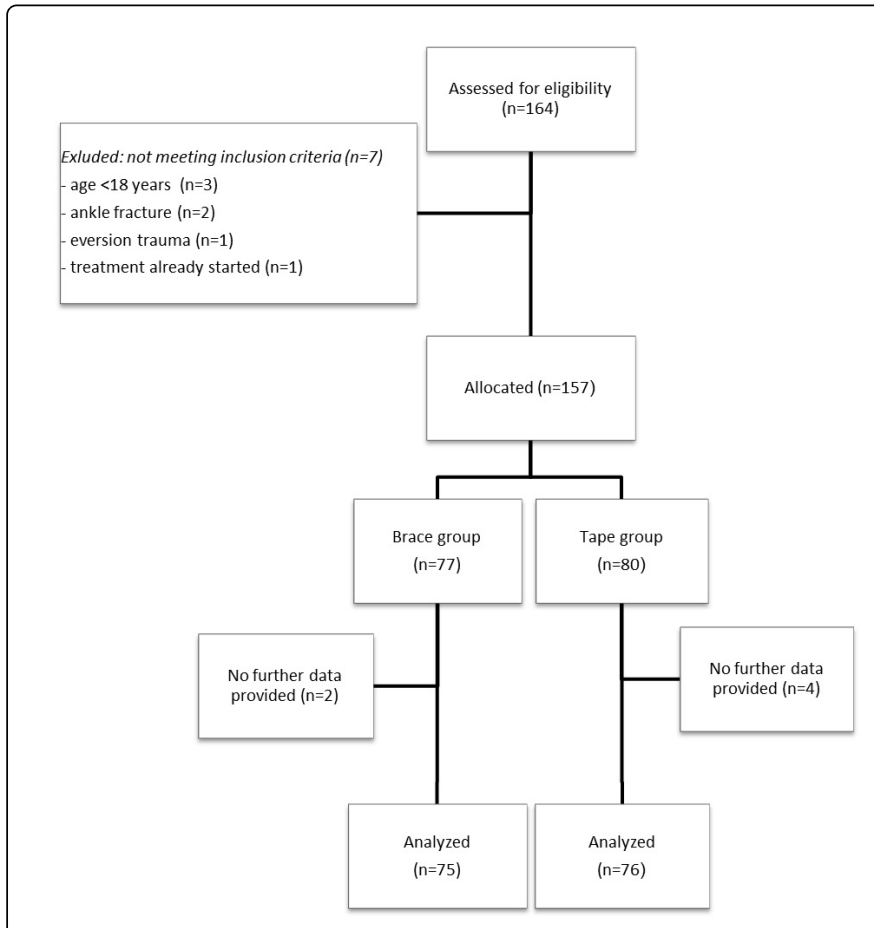

Figure 1: Flowchart of research groups.

The mean age of the 151 included participants was 31.1 years (range 18 to 64 years); 66 participants (44\%) were female. The allocated treatment started on average 6.0 days (SD 2.3) and 5.9 days (SD 2.0) after the initial injury in respectively the brace and tape group. No significant differences were found between the two groups at baseline (Table 1).

\begin{tabular}{|l|l|l|}
\hline Characteristics & Brace (n=75) & Tape (n=76) \\
\hline Gender, male (\%) & $41(55 \%)$ & $44(58 \%)$ \\
\hline Age, mean years (SD) & $30.4(11.1)$ & $31.7(12.2)$ \\
\hline Severity of ankle sprain ${ }^{a}$ & \multicolumn{2}{|l|}{} \\
\hline Mild (\%) & $26(35 \%)$ & $17(22 \%)$ \\
\hline Moderate (\%) & $38(51 \%)$ & $45(59 \%)$ \\
\hline Severe (\%) & $11(15 \%)$ & $14(18 \%)$ \\
\hline History of ankle sprain & & \multicolumn{2}{|l}{} \\
\hline Yes, n (\%) & $32(43 \%)$ & $24(29 \%)$ \\
\hline No, n (\%) & $32(43 \%)$ & $42(55 \%)$ \\
\hline Unknown, n (\%) & $11(15 \%)$ & $12(16 \%)$ \\
\hline
\end{tabular}


Citation: Kemler E, Krist MR, Van de Port IGL, Hoes AW, Ardine de Wit G, et al. (2016) Economic Evaluation of a Soft Ankle Brace Compared to Tape in Acute Lateral Ankle Ligamentous Sprains. Clin Res Foot Ankle 4: 212. doi:10.4172/2329-910X.1000212

Page 4 of 8

\begin{tabular}{|l|l|l|}
\hline Sports participants & $65(87 \%)$ & $63(83 \%)$ \\
\hline $\begin{array}{l}\text { Time from injury to start of treatment } \\
\text { (days) }\end{array}$ & $6.0(2.3)$ & $5.9(2.0)$ \\
\hline Patients with paid jobb & $66(88 \%)$ & $64(84 \%)$ \\
\hline Type of work (sitting n (\%)) & $35(53 \%)$ & $36(56 \%)$ \\
\hline Mean hours of paid work (SD) & $28.4(15.3)$ & $25.9(16.7)$ \\
\hline Students & $17(22 \%)$ & $23(30 \%)$ \\
\hline Mean hours of study (SD) & $23.9(12.4)$ & $26.4(16.7)$ \\
\hline
\end{tabular}

Table 1: Baseline characteristics treatment groups.

${ }^{\text {aSee }}$ appendix B

b25 students had a paid job $($ brace $=11$, tape $=14)$

\section{Effects of intervention}

Within 52 weeks after the initial trauma, 16 of the 75 participants $(21 \%)$ in the brace group compared to 17 of the 76 participants $(22 \%)$

in the tape group reported a re-injury, corresponding to a risk difference of $1.0 \%$ (95\% CI $-12 \%$ to $14 \%$ and a relative risk of 1.0 (95\%CI 0.5 to 1.8$)$.

\section{Cost effectiveness}

Table 2 shows the unit costs, volumes of healthcare resources use and mean costs per patient for both treatment groups. The mean total costs were $€ 1,639$ (SD 2,271; brace group) and $€ 1,846$ (SD 2,624; tape group). After bootstrapping, the mean total costs were $€ 1,634$ (SD 261) per patient in the brace group and $€ 1,846$ (SD 296) per patient in the tape group (Table 3 ). The mean difference was not statistically significant (-€212 (95\%CI -854 to 436). Direct healthcare costs with a mean difference of $€ 94$ ( $95 \% \mathrm{CI}-116$ to 341$)$ and indirect nonhealthcare costs with a mean difference of $-€ 315$ (95\%CI -846 to 198) were not significantly different between the groups. The direct nonhealthcare costs per patient were lower in the intervention group with a mean difference of $-€ 31$ (95\%CI -49 to -15$)$. The mean difference in total costs was mainly caused by a difference in indirect non-health care costs ( $€ 973$ in the brace group compared to $€ 1,289$ in the tape group).

\begin{tabular}{|c|c|c|c|c|c|}
\hline & \multirow[b]{2}{*}{ Cost per Unit } & \multicolumn{2}{|c|}{ Brace $(n=75)$} & \multicolumn{2}{|c|}{ Tape $(n=76)$} \\
\hline & & Volumes & Mean costs $(€ ; \mathrm{SD})$ & Volumes & $\begin{array}{l}\text { Mean costs } \\
(€ ; S D))\end{array}$ \\
\hline \multicolumn{6}{|l|}{ Intervention costs } \\
\hline Accidents and Emergency (one visit) ${ }^{a}$ & 151.00 & - & 151.00 & - & 151.00 \\
\hline General practitioner (one visit) ${ }^{\mathrm{a}}$ & 28.00 & - & - & - & 28.00 \\
\hline Brace $^{\mathrm{b}} /$ Tape $^{\mathrm{a}}$ & $80.00 / 12.90$ & - & 80.00 & - & 12.90 \\
\hline Intervention costs per patient & & - & 231.00 & - & 191.90 \\
\hline \multicolumn{6}{|l|}{ Direct healthcare costs } \\
\hline General practitioner (per visit) ${ }^{a}$ & 28.00 & 62 & $23.15(55.50)$ & 98 & $36.11(61.14)$ \\
\hline General practitioner (phone consultation) ${ }^{\mathrm{a}}$ & 14.00 & 10 & $1.87(7.39)$ & 22 & $4.05(15.00)$ \\
\hline General practitioner (home consultation)a & 43.00 & 3 & $1.72(14.90)$ & 5 & $2.83(17.67)$ \\
\hline Medical specialist a & 129.00 & 61 & $104.92(244.29)$ & 65 & $110.33(285.52)$ \\
\hline Therapist $\mathrm{a}, \mathrm{c}$ & 36.00 & 531 & $254.88(1028.34)$ & 313 & $148.26(289.85)$ \\
\hline Hospital stay; day care (days) ${ }^{a}$ & 251.00 & 0 & $0(0.0)$ & 1 & $3.30(28.79)$ \\
\hline \multicolumn{6}{|l|}{ Supplementary diagnostics ${ }^{a}$} \\
\hline - Ultrasound & 48.30 & 3 & $1.93(12.40)$ & 2 & $1.27(11.08)$ \\
\hline - Radiograph & 42.70 & 17 & $9.68(29.43)$ & 17 & $9.55(24.75)$ \\
\hline - MRI-scan & 184.50 & 6 & $14.76(78.86)$ & 4 & $9.71(41.47)$ \\
\hline - CT-scan & 180.77 & 1 & $2.41(20.87)$ & 1 & $2.38(20.74)$ \\
\hline - Bone scan & 150.50 & 0 & $0(0.0)$ & 0 & $0(0.0)$ \\
\hline Medication $^{d}$ & Variable $^{d}$ & 7 & $4.85(10.95)$ & 4 & $3.16(13.32)$ \\
\hline Total direct healthcare costs & & & $420.80(1,094.01)$ & & $326.57(580.78)$ \\
\hline Direct non-healthcare costs & & & & & \\
\hline
\end{tabular}


Citation: Kemler E, Krist MR, Van de Port IGL, Hoes AW, Ardine de Wit G, et al. (2016) Economic Evaluation of a Soft Ankle Brace Compared to Tape in Acute Lateral Ankle Ligamentous Sprains. Clin Res Foot Ankle 4: 212. doi:10.4172/2329-910X.1000212

Page 5 of 8

\begin{tabular}{|c|c|c|c|c|c|}
\hline Complementary medicine (per visit) & $\begin{array}{l}\text { According to } \\
\text { Patient specification }\end{array}$ & 4 & $3.33(21.31)$ & 17 & $7.50(65.38)$ \\
\hline $\begin{array}{l}\text { Medical devices (i.e., insoles, cold packs, } \\
\text { wheelchair) }\end{array}$ & $\begin{array}{l}\text { According to } \\
\text { Patient specification }\end{array}$ & 0.2 & $6.39(23.23)$ & 0.9 & $32.66(57.31)$ \\
\hline Total direct non-healthcare costs & & & $9.72(30.83)$ & & $40.16(84.04)$ \\
\hline \multicolumn{6}{|l|}{ Indirect non-healthcare costs } \\
\hline Absenteeism - paid work ${ }^{f}$ & See Appendix A & 2547 & $844.50(1514.89)$ & 3090 & $1005.45(2008.63)$ \\
\hline Absenteeism - unpaid work & 12.50 & 672 & $112.00(205.43)$ & 1564 & $257.24(427.37)$ \\
\hline Absenteeism - school & 8.07 & 198 & $21.30(117.33)$ & 237 & $25.17(69.51)$ \\
\hline Total indirect non-healthcare costs & & & $977.81(1,600.44)$ & & $1287.86(2284.50)$ \\
\hline \multicolumn{6}{|l|}{ Total costs } \\
\hline Total costs per patient & & & $1,639.32(2,270.51)$ & & $1,846.49(2,623.70)$ \\
\hline
\end{tabular}

Table 2: Mean (standard deviation) intervention costs, direct healthcare, direct non-healthcare costs, indirect non-healthcare and total costs $(€)$ for both treatment groups.

aPrices according to Dutch guidelines for health care costs [26]

${ }^{b}$ Price for the soft brace obtained from the manufacturer

'Including cost for consultations with the physiotherapist, manual therapist, occupational therapist and caesar therapist

${ }^{\mathrm{d}}$ Drug prices according to the Pharmacotherapeutical Compass as provided by the Dutch Healthcare Insurance Board [27]

${ }^{e}$ Out-of-pocket costs for use of complementary medicine and medical devices were registered by the patient

fIndirect costs for paid work was calculated by age and sex specific income of the Dutch population [26]

\begin{tabular}{|c|c|c|c|c|c|}
\hline & \multirow[b]{2}{*}{ Brace $(n=75)$} & \multirow[b]{2}{*}{ Tape $(n=76)$} & \multicolumn{3}{|l|}{ Bootstrap } \\
\hline & & & Mean difference & \multicolumn{2}{|c|}{$95 \% \mathrm{Cl}$ of difference } \\
\hline & & & & Lower & Upper \\
\hline Intervention costs & 231.00 & 191.90 & 39.10 & & \\
\hline Direct healthcare costs & $419.86(123.74)$ & $325.64(65.76)$ & 94.22 & -116.37 & 340.54 \\
\hline Direct non-healthcare costs & $9.75(3.52)$ & $40.36(9.70)$ & -30.61 & -48.94 & -14.81 \\
\hline Indirect non-healthcare costs & $973.42(184.92)$ & $1,288.53(256.79)$ & -315.12 & -845.87 & 197.65 \\
\hline Total costs ${ }^{a}$ & $1,634.03(261.13)$ & $1,846.43(295.54)$ & -212.41 & -854.20 & 436.45 \\
\hline
\end{tabular}

Table 3: Mean (SD) of costs per patient in Euro and mean differences (95\% confidence intervals $)^{\mathrm{a}}$ between treatment groups in one year. a obtained by calculating bootstrap confidence intervals

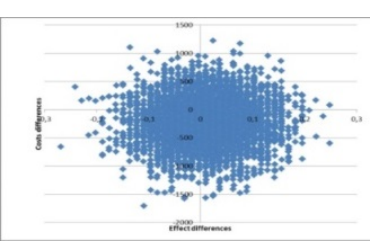

Figure 2: Cost-effectiveness plane presenting costs and effect pairs after bootstrapping (5000 samples).

From a cost perspective, the ankle brace was associated with fewer costs in $71 \%$ of bootstrap replicates. The cost-effectiveness plane with all incremental cost effectiveness ratios (5000 bootstrap samples) is presented in Figure 2. The bootstrap analyses (Table 3) showed that treatment with a soft ankle brace was cost-saving and more effective in $38 \%$ of the bootstrap replicates and cost-saving but less effective in $33 \%$.

\section{Sensitivity analysis}

Four sensitivity analyses were performed (Table 4). Three of the four sensitivity analyses underline the results of the primary analysis showing that the soft ankle brace is less expensive (in 56\% to $87 \%$ of the bootstrap replicates). 


\begin{tabular}{|c|c|c|c|c|c|c|}
\hline Analyses & $\begin{array}{l}\Delta \text { Cost }(€) \\
(95 \% \mathrm{Cl})\end{array}$ & $\begin{array}{l}\Delta \text { Effect }(€) \\
(95 \% \mathrm{Cl})\end{array}$ & North East\# & South Eastt & South West¥ & North West‡ \\
\hline $\begin{array}{l}\text { Base case analysis: } \\
\text { Societal perspective }\end{array}$ & $\begin{array}{l}-212 \\
(-854 \text { to } 436)\end{array}$ & $\begin{array}{l}0.0099 \\
(-0.0960 \text { to } 0.1167)\end{array}$ & 0.16 & 0.38 & 0.33 & 0.13 \\
\hline $\begin{array}{l}\text { Sensitivity analyses: } \\
\text { Healthcare perspective }\end{array}$ & $\begin{array}{l}132 \\
(-81 \text { to } 380)\end{array}$ & $\begin{array}{l}0.0105 \\
(-0.0960 \text { to } 0.1168)\end{array}$ & 0.47 & 0.12 & 0.06 & 0.36 \\
\hline \multirow[t]{2}{*}{ Complete cases } & $\begin{array}{l}-486 \\
(-1,157 \text { to } 208)\end{array}$ & $\begin{array}{l}0.0384 \\
(-0.0775 \text { to } 0.1448)\end{array}$ & 0.09 & 0.64 & 0.24 & 0.03 \\
\hline & $\begin{array}{l}-55 \\
(-660 \text { to } 552)\end{array}$ & $\begin{array}{l}0.0089 \\
(-0.0963 \text { to } 0.1167)\end{array}$ & 0.26 & 0.31 & 0.25 & 0.18 \\
\hline $\begin{array}{l}\text { Excluding patients with other ankle } \\
\text { injuries than acute lateral ankle } \\
\text { sprain }\end{array}$ & $\begin{array}{l}-175 \\
(-858 \text { to } 488)\end{array}$ & $\begin{array}{l}-0.0227 \\
(-0.1327 \text { to } 0.0770)\end{array}$ & 0.12 & 0.23 & 0.43 & 0.22 \\
\hline
\end{tabular}

Table 4: Results of sensitivity analyses.

$\Delta$ Cost is the mean difference in the costs of 5000 bootstrapped samples

$\Delta$ Effect is the mean difference in the effect of 5000 bootstrapped samples

\# Soft brace is more effective and more costly than tape

T Soft brace is more effective and less costly than tape

$¥$ Soft brace is less effective and less costly than tape

$\neq$ Soft brace is less effective and more costly than ankle tape

\section{Discussion}

In this study comparing the effect and costs of soft brace treatment and ankle tape treatment in ALALS, a non-significant injury reduction was accompanied by a non-significant cost saving. However, according to the cost-effectiveness analysis, treatment with a soft ankle brace was less expensive in $71 \%$ of the 5000 samples. In $29 \%$ ankle brace treatment was cost-saving and more effective. Three of the four sensitivity analyses underline the results of the primary analysis showing that the soft ankle brace is less expensive (in $56 \%$ to $87 \%$ of the bootstrap replicates). Importantly, this difference is mainly attributable to productivity losses which occur at the own expense of patients.

Previous studies, on the cost-effectiveness [29] and cost-savings [30] of external supports in the treatment of ALALS, showed significant reduction of direct and/or indirect costs in favor of the ankle brace. Leanderson and Wredmark [30] found a significant reduction in sick leave, resulting in lower indirect costs, with an Air-Stirrup ankle brace treatment compared to compression bandage. In a study of Lamb et al. $[15,29]$ regarding severe ankle sprains, the Aircast ${ }^{\bullet}$ brace and 10-day below-knee cast ${ }^{\text {th }}$ were more cost-effective, in terms of costs per quality adjusted life years (QALYs), compared to Tubigrip ${ }^{\circ}$. In the current study, the soft brace was not more cost-effective than an ankle tape after one year of follow-up. However, our study differs from the aforementioned studies with respect to the kind of ankle brace used, the reference treatment (tape versus compression bandage in other studies) and the severity of ankle sprains.

Verhagen et al. estimated the mean total costs (direct health care costs and indirect non-health care costs) of one ankle sprain at $€ 360.60$ [5]. The mean costs per patient in our study were much higher. In our study costs are reported per participant and not per ankle sprain. All 151 participants in our study had an ankle sprain (the initial ankle sprain), 33 participants (20\%) had at least one ankle sprain recurrence.
Furthermore, all our participants sought medical treatment for their initial ankle sprain (inherent to the inclusion criteria), compared to $79 \%$ only in the study by Verhagen et al. [5]. In 2013 mean direct medical costs and indirect non-healthcare costs related to ankle injuries treated at ED's in the Netherlands were $€ 1,710$ for patients aged 15-34 and €3,070 for patients aged 35 and older [31]. As the mean age of our study population was 31 , these costs are more in line with our results.

As in the other studies $[5,26,32]$, the majority of the costs were attributable to the costs due to productivity loss. From an employer's perspective, the soft ankle brace might be preferred over ankle tape treatment: the soft brace tends to result in a quicker return to work or school. Patients might have benefit from the comfort and adjustability of the brace in the prevention of absenteeism. In a systematic review of Kemler et al. [33] no evidence for quicker return to work for the ankle brace was found. Further research should focus more specifically on the severity of the ankle sprain and type of work in relation to work absenteeism in the first period of an ankle sprain injury.

In this study, the information about recurrent ALALS and costs were collected by using structured online cost questionnaires. The use of self-reporting methods for recurrent ALALS has been used in previous trials on treatment and prevention of ankle re-sprains [34,35] and is common in economic evaluations alongside clinical trials. With respect to recall of volumes of resources used and out-of-pocket costs, it has been shown that the use of cost-questionnaires can replace cost dairies with a recall period up to 6 months [36]. We therefore feel confident that our economic evaluation is reliable.

Missing costs data were imputed according to the last observation carried forward' principle. Although multiple imputation is often the favorable technique, we assume that our method did not significantly influence the final results as only $3.9 \%$ of our data points was missing. 
From a societal perspective, the use of a soft brace in the treatment of ALALS did not lead to additional costs despite of the higher purchasing costs for the ankle brace. These higher brace treatment costs seem to be negated by lower mean non-healthcare costs per patient treated with a soft brace compared to patients with ankle tape treatment. In this study, the costs for the soft ankle brace were regarded as intervention costs. In daily life, the costs of ankle braces are usually not or hardly ever reimbursed by health care insurance companies in the Netherlands. Treatment with a soft ankle brace will increase the direct non-healthcare costs (out of pocket costs for patients). Despite our finding that using the soft brace is associated with lower societal costs, these higher out of pocket costs might be a barrier for the use of ankle braces in treating ankle sprains. Other arguments, such as patient comfort and lifestyle activities may become important in the choice to go for brace or tape.

\section{Acknowledgement}

None.

\section{Funding}

This study was partially funded by NEA International, manufacturer of the Push Med ankle brace.

\section{Statement of financial disclosure and conflict of interest}

The content of this report is solely the responsibility of the authors and does not necessarily represent the official view of NEA International. We declare that we have no conflict of interest. Prof. FJG Backx declares: Nea International has given unrestricted financial support to initiate and perform this study. Furthermore they offered the ankle braces (type Push Med) aimed at the intervention. We fulfilled this study without any influence or interference of the sponsor.

\section{References}

1. Kemler E, Van de Port I, Valkenberg H, Hoes AW, Backx FJ (2015) Ankle injuries in the Netherlands: Trends over $10-25$ years. Scand J Med Sci Sports 25: 331-337.

2. Bridgman SA, Clement D, Downing A, Walley G, Phair I, et al. (2003) Population based epidemiology of ankle sprains attending accident and emergency units in the West Midlands of England, and a survey of UK practice for severe ankle sprains. Emerg Med J 20: 508-510.

3. Holmer P, Sondergaard L, Konradsen L, Nielsen PT, Jorgensen LN (1994) Epidemiology of sprains in the lateral ankle and foot. Foot Ankle 15: $72-74$.

4. Factsheet on ankle injuries (in Dutch). Amsterdam: Consumer Safety Institute, 2012.

5. Verhagen E, Van Tulder M, Van der Beek AJ, Bouter L, van Mechelen W (2005) An economic evaluation of a proprioceptive balance board training programme for the prevention of ankle sprains in volleyball. $\mathrm{Br} J$ Sports Med 39: 111-115.

6. Van Rijn RM, Van Os AG, Bernsen RM, Luijsterburg PA, Koes BW, et al. (2008) What is the clinical course of acute ankle sprains? A systematic literature review. Am J Med 121: 324-331.

7. Verhagen RA, de Keizer G, van Dijk CN (1995) Long-term follow-up of inversion trauma of the ankle. Arch Orthop Trauma Surg 114: 92-96.

8. Anandacoomarasamy A, Barnsley L (2005) Long term outcomes of inversion ankle injuries. Br J Sports Med 39: e14.

9. Hertel J (2000) Functional instability following lateral ankle sprain. Sports Med 29: 361-371.
10. Safran MR, Benedetti RS, Bartolozzi AR, Mandelbaum BR (1999) Lateral ankle sprains: a comprehensive review - Part 1: etiology, pathoanatomy, histopathogenesis, and diagnosis. Med Sci Sports Exerc 31: S429-S437.

11. Jones MH, Amendola AS (2007) Acute treatment of inversion an ankle sprains - Immobilization versus functional treatment. Clin Orthop Relat Res 455: 169-172.

12. Goudswaard AN, Thomas S, Van den Bosch WJHM (2009) NHGstandaard Enkeldistorsie. Houten, Bohn Stafleu van Loghum. pp: 1101-1108.

13. Kannus P, Renstrom P (1991) Treatment for acute tears of the lateral ligaments of the ankle. Operation, cast, or early controlled mobilization. J Bone Joint Surg Am 73: 305-312.

14. Kerkhoffs GM, Struijs PA, Marti RK, Blankevoort L, Assendelft WJ, et al. (2003) Functional treatments for acute ruptures of the lateral ankle ligament : A systematic review. Acta Orthop Scand 74: 69-77.

15. Lamb SE, Marsh JL, Hutton JL, Nakash R, Cooke MW, et al. (2009) Mechanical supports for acute, severe ankle sprain: a pragmatic, multicentre, randomised controlled trial. Lancet 373: 575-581.

16. Kerkhoffs GM, Rowe BH, Assendelft WJ, Kelly K, Struijs PA, et al. (2002) Immobilisation and functional treatment for acute lateral ankle ligament injuries in adults. Cochrane Database Syst Rev 3: CD003762.

17. Kerkhoffs GM, Rowe BH, Assendelft WJ, Kelly K, Struijs PA, et al. (2001) Immobilisation for acute ankle sprain - A systematic review. Arch Orthop Trauma Surg 121: 462-471.

18. Petersen W, Rembitzki IV, Koppenburg AG, Ellermann A, Liebau C, et al. (2013) Treatment of acute ankle ligament injuries: a systematic review. Arch Orthop Trauma Surg 133: 1129-1141.

19. Kerkhoffs GM, Van den Bekerom M, Elders LA, van Beek PA, Hullegie WA, et al. (2012) Diagnosis, treatment and prevention of ankle sprains: an evidence-based clinical guideline. Br J Sports Med 46: 854-860.

20. Martin RL, Davenport TE, Paulseth S, Wukich DK, Godges JJ, et al. (2013) Ankle stability and movement coordination impairments: ankle ligament sprains. Clinical practice guidelines linked to the international classification of functioning, disability and health from the orthopaedic section of the American physical therapy association. JOSPT 43: A1-A40.

21. Kerkhoffs GM, Handoll HH, De Bie R, Rowe BH, Struijs PA (2007) Surgical versus conservative treatment for acute injuries of the lateral ligament complex of the ankle in adults. Cochrane Database Syst Rev 18: CD000380.

22. Lin CW, Uegaki K, Coupé VMH, Kerkhoffs GM, van Tulder MW (2013) Economic evaluations of diagnostic tests, treatment and prevention for lateral ankle sprains: a systematic review. Br J Sports Med 47: 1144-1199.

23. Kemler E, van de Port I, Schmikli S, Hoes A, Huisstede B, et al. (2015) Effects of soft bracing or taping on a lateral ankle sprain: a nonrandomised controlled trial evaluating recurrence rates and residual symptoms at one year. J Foot Ankle Res 8: 13.

24. http://nhg.artsennet.nl/kenniscentrum/k_richtlijnen/k_nhgstandaarden/ Samenvattingskaartje-NHGStandaard/M04_svk.htm

25. Hakkaart- van Roijen L, Tan SS, Bouwmans CAM (2010) Handleiding voor kostenonderzoek, methoden en standaard kostprijzen voor economische evaluaties in de gezondheidszorg. Diemen: College voor zorgverzekeringen.

26. Drummond MF, Sculpher MJ, Torrance GW, O'Brien BJ, Stoddart GL (2005) Methods for the economic evaluation of health care programmes. Oxford University Press.

27. van Loenen AC (2009) Farmacotherapeutisch kompas. College voor zorgverzekeringen. Amstelveen: Bohn Stafleu van Loghum.

28. Black WC (1990) The Ce Plane: a graphic representation of costeffectiveness. Med Decis Making 10: 212-214.

29. Lamb SE, Nakash RA, Withers EJ, Clark M, Marsh JL, et al. (2005) Clinical and cost effectiveness of mechanical support for severe ankle sprains: design of a randomised controlled trial in the emergency department [ISRCTN 37807450]. BMC Musculoskelet Disord 6: 1. 
Citation: Kemler E, Krist MR, Van de Port IGL, Hoes AW, Ardine de Wit G, et al. (2016) Economic Evaluation of a Soft Ankle Brace Compared to Tape in Acute Lateral Ankle Ligamentous Sprains. Clin Res Foot Ankle 4: 212. doi:10.4172/2329-910X.1000212

Page 8 of 8

30. Leanderson J, Wredmark T (1995) Treatment of acute ankle sprain Comparison of a semi-rigid ankle brace and compression bandage in 73 patients. Acta Orthop Scand 66: 529-531.

31. VeiligheidNL (2015) Business case ankle sprains.

32. Cooke MW, Marsh JL, Clark M, Nakash R, Jarvis RM, et al. (2009) Treatment of severe ankle sprain: a pragmatic randomised controlled trial comparing the clinical effectiveness and cost-effectiveness of three types of mechanical ankle support with tubular bandage. The CAST trial. Health Technol Assess 13: 1-121.

33. Kemler E, Van de Port I, Backx F, van Dijk CNl (2011) A systematic review on the treatment of acute ankle sprain brace versus other functional treatment types. Sports Med 41: 185-197.
34. Hupperets MDW, Verhagen EALM, Van Mechelen W (2009) Effect of unsupervised home based proprioceptive training on recurrences of ankle sprain: randomised controlled trial. BMJ 339: b2684.

35. Van Rijn RM, Van Os AG, Kleinrensink GJ, Bernsen RM, Verhaar JA, et al. (2007) Supervised exercises for adults with acute lateral ankle sprain: a randomised controlled trial. Br J Gen Pract 57: 793-800.

36. Van den Brink M, Van den Hout WB, Stiggelbout AM, Putter H, van de Velde CJ, et al. (2005) Self-reports of health-care utilization: Diary or questionnaire? Int J Technol Assess Health Care 21: 298-304. 